\title{
NEW BUSINESS MODELS GENERATED BY TECHNOLOGICAL INNOVATION
}

\author{
Xhorxhina VANGJEL \\ Department of Economy and Business, Faculty of Economics, The University of \\ Oradea, Oradea, Romania \\ xhorxhinavangjel@yahoo.com
}

\begin{abstract}
The evolution of technology has caused a revolution in almost every fragment of the entrepreneurial sector, especially in terms of adapting business models to innovation. The management of a business in a competitive market has become increasingly unpredictable. Leadership style has changed the way the business model is framed through modern strategic thinking or management. By applying new information technologies, businesses need to constantly reflect in order to redesign the business models they use. Business models under the pressure of time changes have changed the format of operation and approach, depending on the "innovation" factor. Today, companies around the world feel under direct pressure to operate in efficient solutions, designed to fully adapt to the various and comprehensive strategic business management activities. As a result of technological evolution, organizations find it easier to intervene in the markets, to increase their operating segments in the market, as well as to change the forms of the way the product is delivered to the customer. This has brought uncertainty in their managerial work but has also significantly facilitated the environment in which businesses operate. Even for many businesses technological development is the motto of their existence. Many companies themselves have been established on the basis of internet technology while from many others technological evolution is exploited to take advantage of another level in the market. The use of the software industry in business is considered a key factor of computerization due to the economic benefits, expressed in fast and intermediary transactions, cost reduction, revenue growth, competitive advantages, product diversity and saving of nonrenewable resources. Studying the impact of technology and innovation on business models is essential to explore how companies innovate, need and should innovate the business model. The purpose of this paper is to advance research on the perspective offered by innovation in the business model. The aim is to emphasize the importance of technological development in the creation of digital businesses, hoping to inspire managers and entrepreneurs to compete in the market not only by applying the latest technology available, but also by creating their innovations to make their business more profitable and more sustainable. The novelty of this study corresponds to a general analysis of "modern business models", in the way how business models in combination with technological evolution, mature and bring to the stage new business models, those provoked by technological trends.
\end{abstract}

Keywords: technological innovation; business models, digital enterprises, internationalization, e-business, e-commerce.

JEL classification: M10; O30 


\section{Introduction}

The complexity of the current market, the production and transmission of material goods, the application of new technologies, the raising of awareness, responsibility and social requirements, have inevitably influenced the productive philosophy of companies.

Once a new business is initiated, it is destined to use and adapt a certain business model that will serve to design the internal organization and value creation for the business. Naturally, under the impact of technology evolution, businesses need to better reconceptualize internal organizational activities, improve them in relation to time changes, in parallel with new developments and above all deepen them in the managerial organization of work.

Managers and entrepreneurs under the influence of innovation and rapid development of the global market, spontaneously impose change on the company."Innovative managers" explore new products for existing markets. They also explore new markets for existing products. Meanwhile companies are exploring new products for new markets. (Edison \& Wang 2018)

Under the inspiration of various promotional techniques, companies tend to continuously publicize their own "identity" on the market.Leaders and managers of organizations are constantly exploring new business models that have the potential to positively increase their competitive performance in the market, as well as to increasingly influence consumer behavior.

The literature review shows that researchers are continually linking business models to change processes.An interesting definition of innovation in business models is found in the principles of Joseph Schumpeter, known for inventing the term "creative destruction" in the field of economics. (Sako 2012)

Thus, the innovation of business models translates into a new market, a recreation of the way businesses produce, a new philosophy regarding the way businesses do business. In this sense (Sako 2012) implies a close and inseparable link between business models and new technology.So it highlights modern arguments, saying that if a new technology does not take the form of a product launched on the market, then the technology remains unused and therefore we have no value created.So, based on these arguments we can say that this author sees in a way business models as a catapult of technological mechanisms and processes based on value creation.

Integration of work processes, influenced by the digitization of processes refers to the need for an updated digital infrastructure.Adapting production processes to industrial revolutions and technological changes means constantly replacing equipment and updating the communication networks that help the production system.

Considering that every technological development brings always more advanced and automated methods in production or provision of services, is constantly emphasized necessity for continuous investment in equipment, production infrastructure and systems.

Technological transformation, healthy fiscal and capital practices, increase flexibility, renew more than ever business models in constant change.

Many companies have created business websites which play an essential role in the internal structural relations of the firm or even in promoting the efficiency of external relations. 
The use of websites serves for employees in the company as a regulator of communication and dissemination of information via email.

This facilitates communication between the entrepreneur, manager or staff. It also affects the efficiency of the use of the supply network.Makes information exchanges with suppliers, distributors or vendors more manageable. The customer also has the opportunity to get acquainted with a descriptive picture about the company, the products it offers, serving at the same time as a mechanism to communicate with the company about various services around the framework of what the company offers.

\section{Digital Challenge for Business Innovation: Becoming a Modern Digital Enterprise}

Once change towards digitalization in the business context was conceived as a limited distribution phenomenon and somewhat of a "myth", but in recent decades has become an inevitable necessity, a non-negotiable need.

The digital transformation and Internet as in any sector of the economy, has "occupied" also the environment where businesses develop commercial activity. Leadership style in organizations has changed "behavior". Because in the world of digital business, entrepreneurs and managers are the first to experience the taste of change. And it is precisely these who are the first to lead these changes. Being already not just a choice, but rather a purpose, the challenge of adapting the organization to the implementation of new technologies in business is inevitable.

The paradigm of "digitalization" in the economic context includes a set of processes of using digital technologies that improve a business model, with the aim of creating new opportunities to use the potential of the firm and that is finalized in higher revenues for the organization. (Acedo \& Jones, 2007)

Increasing customer expectations for the speed, range and quality of product or service delivery, mean the development of new business restructuring capabilities and processes.

Due to the technological evolution in the economic sector, businesses have changed not only the existing infrastructure, systems and structures, but also the strategy of the company itself, following a complete change in the current business model.

Information, communication technologies, evolution and digital technology is creating huge benefits in terms of performance that different companies show in the market. According to a report from the Harvard Business School, digitalization is presenting the integrated use of analytics, big data, the cloud, the Internet of Things "loT", mobile phones, applications, which together are driving the pace of significant and long-term changes in the development of the business sector. According to the report, now "Digital transformation in the economy has become the new normal, a inevitable innovation and now this is not more a preference but a necessary choice, it is a matter of survival." (Kerschberg, 2017)

Business Roundtable (2007), an association of senior executives (CEOs) of United States companies emphasizes the importance that companies must place on their online business. For them it is necessary that "companies assess their dependence on the Internet, in terms of the prospect that the business is able to provide vital operations in function, as soon as possible even in the event of a major disorder or disruption of the Internet proliferation". As the optimal management of such a 
situation, it is vital to minimize the inconvenient consequences of business as a whole, but also to minimize the negative impact on the economy and overall security of the country. Also Business Roundtable (2007) concludes that "business is not able to handle with prudence all significant internet disruptions" being vulnerable to any change in this regard.

\section{Harmonizing Business With IT: Web 2.0}

The digital infrastructure has created space for the creation of new business models, encouraging "the conversion of new technologies into commercial value". (Sako 2012). How you use e-commerce or web applications, simultaneously affects a company's cost and revenue.

The use of "E-Commerce", "Web 2.0", "Cloud services" or the "pay as you go" calculation model, influences the possible development of new business models, mediating both sides of trade, producer-consumer and reduces the need for an expensive infrastructure. In the literature, the current emphasis is placed on Web 2.0 technology, in international marketing strategies and dimensions.

The term Web 2.0, widely used by Tim O'Reilly and CEO of O'Reilly Media, has been defined as a set of economic, social and technological trends that underlie the next generation of the Internet (Musser and O'Reilly2006). According to this study, the Web 2.0 application is based on four distinct characteristics: The website as a platform; Content and data impose applications as a "dynamic force"; Such an architectural framework encourages users to contribute; A cheap software, easy to build and use, where its approval should be seen more as an opportunity than as a cost.

Studies that talk about the Web 2.0 application are few, but it seems that this application has a growing trend. Considering that technological developments are advancing day by day, of course new forms of e-commerce application will appear. This will definitely stimulate the competitiveness of enterprises and enable competitive advantages in the global market (Constantinides 2010)

Through the facilities offered by the Web 2.0 application, companies are also given space to balance deficiencies in resources or ideas by using external resources, which involves business strategy. (Jim Bell, Sharon Loane 2010) The creation of social networking sites known as social media such as Facebook, Whatsapp, Viber, YouTube, Twitter, LinkedIn, Instagram, Qzone, Tumblr, Line etc., have led companies to redefine the role of technology in terms of development and promoting in the online world the product that the business offers.

\section{Moderated business models by technology: E-business, E-commerce and E-marketing}

Precisely from the fact that business development is increasingly based on the use of the Internet, seen in the positive aspect this allows entrepreneurs to keep their audience up to date with any latest business trends or changes. So by informing the audience, the use of technology and the Internet serves to keep consumers closer to the business.Customers now quickly access online shopping websites and get the information they consider important.Thus the consumer has more access to the image of the business and to the recognition of the products launched on the market at different times by the firms. The growing interest of 
consumers to be informed in real time, has prompted many companies to develop "E-business", "E-commerce" or to apply "E-marketing".

In recent decades, the framing and commitment of businesses in the context of the Internet has moderated business models by influencing the development of a new business model, that of "e-business".

E-business refers to the beginning of the planning and implementation of the electronic business process. (Meier \& Stormer 2009)

Five tools on the Internet are proposed with significant capabilities influencing the success of e-business: product selection by the buyer, online payment, credibility displayed by the seller, shopping trips and errors in shipping the product.At the same time, four main objects are identified on the Internet that affect the success of e-business: the ease of making purchases, the ecology of the Internet, tradecustomer interaction and the value of the product.(Torkzadeh \& Dhillon, 2002)

In the literature studies regarding e-business models, three different classifications are defined: e-procurement, e-organization and e-commerce. To rich this result, the nine main types of business model most often found in the e-commerce literature have been studied by authors of the literature: Brokerage Model, Advertising Model, Infomediary Model, Merchant Model, Affiliate Model, Manufacturer Model, Community Model, Subscription Model, Utility Model(Abdollahi, 2011).

If we mention a classic, traditional business activity, we say that it consists of four main elements: Product Offering, Product Ordering, Payment of the Product, Product delivery.At the moment that the realization of one of these constituent elements is done on the Internet, then we are dealing with e-commerce. ECommerce is positioned as one of the main trends of recent years.Many people have built their own online stores and they trade their goods worldwide. After creation, there is a lot of work to be done for e-commerce management, because building a website is just the beginning.E-commerce is not a simple online store, but it is a real company and should be thought and managed as such.

Website should be designed in accordance with "business-user" requirements. Collaboration with all project stakeholders: development team, business owner, the quality of the website factors, consumers/users of website, is very important. (Lee \& Kozar 2006)

The concept of "e-commerce" consists of everything that refers to the way of doing business online quickly, without cost, without barriers being applied on a global scale and in real time twenty-four hours a day without applying the same sales method as in the traditional business model. E-commerce has intensively impacted businesses by improving infrastructure and resource allocation. It has obviously created an economy with tremendous potential to improve the efficiency of global trade because the competitive market conveys flexibility, a wide range of products, drastic cost reductions and significant profit margins. (Javalgi \& Ramsey 2001)

There are a number of features of e-commerce that frames companies to move beyond the traditional model of doing business and get involved in online business models: availability, interactivity, interaction, global spread, universal standards where the standard called the Internet is the basis, wide range of applications, density of information and communication;personalization / image of the firm and logo. (Laudon \& Laudon, 2007).

The Internet and doing business through e-commerce offers consumers a variety of products to choose, and not only that, because it also serves as the perfect option for trading. 
From the moment that we talk about business, we are also talking about marketing. The term marketing refers to the identification and satisfaction of specific human and social needs, specifically as defined by Philip Kotler, "Marketing can be described as a social process by which individuals and groups get what they need, through the creation, supply and trade offree of valuable products and services. "

The growth of social media has an impact on the world of E-marketing.It does not happen that an organization can not reach customers and their expectations through one social media platform or another.

Creating relationships with the consumer through media or electronic platforms makes the exchange of ideas, products or services more convenient, by simultaneously balancing the pleasures of the seller, as well as the buyer (Ngai, 2003).

E-marketing as an integral part of e-commerce influences brand awareness, creates potential for audience growth and target clientele as well as business promotion. This whole process of business exposure translates into revenue generation for the company. The role of e-marketing is to create an online connection between the company and the target customers, based on the concept of coherence, according to the emotions that the company wants to convey.

\section{The Paradigm of Innovation and Internationalization}

Today, the success of a business in both the internal and external markets is ensured by innovation. Innovation is the main positive driver of economic growth in today's global economy. (Bruland \& Mowery 2004).

The term "open innovation" first used by Chesbrough (2003), highlighted how large companies flexibly combine new technologies from outside the company and those developed within the company to form new business models based on the influence of the technology network.

According to the OECD, product innovation is the process of "performing / creating" something new or "performing / creating" something in a new way. In business, innovation must also include the concept of improvement. So it basically consists of introducing a product / service that is new or that has been significantly improved in terms of features, purpose of its use, mode of operation, image, composition, materials, technical specifications, incorporated software, or evaluation positive by product / service users. (OECD 2005)

In a literature review, researchers saw progress in the role of the Internet in terms of internationalization (Jim Bell, Sharon Loane 2010), concluding on three stages of early and subsequent contributions to Internet use. The Internet in the first stage of early contributions is seen as a "facilitator" factor that has allowed companies to establish a "global presence": Companies have faster and more efficient communication opportunities. The interaction between companies creates opportunities for more accurate information on international markets. The Internet in the second stage of contributions is seen as an "enabling" factor for "new eofferings": Companies conduct transactions online. Companies have the opportunity to constantly introduce new electronic offers. Creating new business models based on changing the network of information and action in supply chains. In recent contributions, the Internet has been seen as a "creator" or "promoter" of innovative opportunities internationally, creating opportunities for "co-creation" and interaction between companies. 


\section{Conclusions}

In economic activities the use of the internet, positively helps businesses to offer their products or services in a wider market with lower transaction costs and reduced investments to reach new clients. In the ranking of the most successful companies in the world lead those companies that stand out first for innovative capabilities. So it is obvious that the most innovative, businesses perform better financially.In the context of the firm's financial performance, leadership style should convey a supportive education about "diffusion of innovation". This will help businesses to understand their position in the market where they really are and to define their objectives more clearly so that they can be positioned where the business has prospects to be positioned. This would also encourage strategic planning of the firm's long-term policies.In the eraof massive internet proliferation, the acquisition of contemporary views, innovation oriented culture and the leadership of companies in the spirit of compromise with innovation,influences them to improve their competitive performance in the global market. The purpose of this paper is to expand the visionary research aspects, regarding the impact of implementation creativity and innovation on business models. In the end, innovation in business models does not have a strict definition, but it is a constant state of disagreement with the "status-quo" of the entrepreneurship. The analysis shows that the approach of innovation in business, increases the vigilance towards responsibilities, often questioning the management and innovation capacities of the firm. In terms of innovation-oriented culture in business models, as an asset that turns competition into an advantage, it is recommended a continuous adaptive manifestation of conformity and functionalization of some concrete steps related to initiatives to apply all formats of software industry in business, in order to ensure high performance.

\section{References:}

1. Abdollahi, G., and Leimstoll, U. (2011), "A Classification for Business Model Types in E-commerce". AMCIS 2011 Proceedings - All Submissions.Paper 88.

2. Acedo, F., and Jones, M. (2007), Speed of internationalization and entrepreneurial cognition: Insights and a comparison between international new ventures, exporters and domestic firms. Journal of World Business, Elsevier, Vol. 42(3), 236-252.

3. Amit, R., and Zott, C. (2012), Creating value through business model innovation.

4. Baden-Fuller, C. and Haefliger, S., (2013), Long range planning, Business models and technological innovation.

5. Bell, J. and Loane, Sh. (2010), New-wave' global firms: Web 2.0 and SME internationalization, Journal of Marketing Management, Vol. 26: 3, pp.213 - 229.

6. Booz\&Co (2013), The 2013 Global Innovation Study: Navigating the digital future.

7. Bruland, K. and Mowery, D. (2004), Innovation through time.

8. Business Roundtable (2007), Growing Business Dependence on the Internet New Risks Require CEO Action. Business. Washington DC. [Online], Available:https://www.yumpu.com/en/document/read/36199934/growing-businessdependence-on-the-internet-new-risks-require- 
9. Cavalcante, S., Kesting, P. and Ulhøi, J. (2011) "Business model dynamics and innovation: (re)establishing the missing linkages", Management Decision, Vol.49, No.8, pp. 1327-1342.

10. Chaffey, D. (2007), E-business and E-commerce Management: Strategy, Implementation and Practice.

11. Chaudhury, A. andKuilboer, JP. (2001), E-business and E-commerce Infrastructure: Technologies Supporting the E-business Initiative.

12. Chesbrough, H. (2003), Open innovation: The new imperative for creating and profiting from technology. Boston: Harvard Business School Press.

13. Chesbrough, H. (2003), Open Innovation: The New Imperative for Creating and Profiting from Technology. Boston: Harvard Business School Press. [Online], Available: https://www.nmit.edu.my/wp-content/uploads/2017/10/Open-Innovationthe-New-Imperative-for-Creating-and-Profiting-from-Technology.pdf

14.Chesbrough, H. (2010), Business model innovation: opportunities and barriers.

15. Constantinides, E. (2010), Connecting Small and Medium Enterprises to the New Consumer: The Web 2.0 as Marketing Tool. IGI Global. DOI:10.4018/978-161520-627-8.ch001

16. Dutta, S. (2012), The Global Innovation Index 2012: INSEAD and WIPO.

17. Edison, H., Wang X., Jabangwe, R., and Abrahamsson, P. (2018), Innovation Initiatives in Large Software Companies:A Systematic Mapping Study, [Online], Available: https://arxiv.org/pdf/1802.05951.pdf

18. Fingar et al. (2003), Extreme Competition:Innovation and the Great 21st Century Business Reformation.

19. Gambardella A. \& McGahan A.M. (2010), Business-model innovation: General purpose technologies and their implications for industry structure. Long Range

Planning, Vol.43, pp. 262-271. [Online], Available:

http://www.businessmodelcommunity.com/fs/Root/8jat2-

1 s2 0 S0024630109000594 main.pdf

20. Javalgi, R., Ramsey, R. (2001), "Strategic Issues of E-Commerce as an

Alternative Global Distribution System”, International Marketing Review, Vol. 18, No. 4, pp. 376-391.

21. Kenneth, L. C. and Jane, L. P. (2014), Management Information Systems, Managing the Digital Firm. New York: Pearson. [Online], Available:

22. Kerschberg, B. (2017), How Digital Disrupts Operations, Business Processes And Customer Experience.

23. Kotler, P. (2003), Marketing Management. 11th Edition, Prentice-Hall, Upper Saddle River, pp.685.

24. Kotler, P., (2007), Marketing Management, Mondadori Editori, Milano.

25. Laudon, J. P., and Laudon, K. C. (2007), Management Information Systems:

Managing the Digital Firm, 10th Edition.

26. Leea, Y., \& Kozarb, K. A. (2006), Investigating the effect of website quality on e-business success: an analytic hierarchy process (AHP) approach. Decision Support Systems, 42(3), 1383-1401.

27. Musser, O'Reilly and The O 'Reilly Radar Team (2006), "Web 2.0 Principles and Best Practices", p.4. [Online], Available:

https://entreprisedigitale.typepad.com/main/files/web20 report excerpt.pdf 28. Ngai, E.W.T., (2003), "Internet marketing research (1987-2000): a literature review and classification", European Journal of Marketing, Vol. 37 No. 1/2. 
29.OECD (2005), Oslo manual guidelines for collecting and interpreting innovation data. Luxembourg: Statistical Office of the European Communities.

30. Sako M. (2012), Technology Strategy and Management, Business Models for Strategy and Inovation, Vol. 55, no. 7.

31. Spieth, P., Schneckenberg, D. and Matzler, K. (2016), R\&D Management, Exploring the linkage between business model (\&) innovation and the strategy of the firm.

32. Torkzadeh, G., and Dhillon, G. (2002), Measuring factors that influence the success of Internet commerce. Information Systems Research, 13(2), 187-204. DOI:10.1287/isre.13.2.187.87

33. Wirtz BW. (2011), Design-Process-Instruments, Business Model Management.

34. Zott, C. and Amit, R. (2007), "Business Model Design and the Performance of Entrepreneurial Firms," Organization Science 18, no. 2: p.181-199. 